\title{
Monitoring body temperature during moderate intensity exercise and inactive recovery in the cold: a pilot study
}

\author{
Emily Procter ${ }^{1,2, *}$, Giacomo Strapazzon ${ }^{2}$, Hannes Gatterer ${ }^{1,2}$, Bernd Wallner ${ }^{2,3}$, \\ Hermann Brugger ${ }^{2} \&$ Martin Burtscher ${ }^{1}$ \\ 1 Department of Sport Science, University of Innsbruck, Austria \\ 2 Institute of Mountain Emergency Medicine, Eurac research, Bozen/Bolzano, Italy \\ 3 Department of Anaesthesia and Intensive Care Medicine, University Hospital Innsbruck, Medical University Innsbruck, Austria \\ * Corresponding author: Department of Sport Science, University of Innsbruck, Fürstenweg 185, 6020 Innsbruck, Austria \\ Email: emily.procter@student.uibk.ac.at
}

\section{ORIGINAL ARTICLE}

Article History:

Submitted $10^{\text {th }}$ May 2018

Accepted $12^{\text {th }}$ October 2018

Published $18^{\text {th }}$ January 2019

Handling Editor:

Arno Schmidt-Trucksäss,

University of Basel, Switzerland

Editor-in-Chief:

Martin Kopp

University of Innsbruck, Austria

Reviewers:

Reviewer 1: Anonymous

Reviewer 2: Anonymous

\section{ABSTRACT}

Exposure to cold ambient conditions during outdoor recreation can lead to significant heat loss. It is unknown how fast body temperature decreases or how fast a person could become hypothermic in cold temperatures. We present a series of pilot tests involving moderate intensity exercise and inactive recovery in the cold to monitor how body temperature changes with exposure to $-10^{\circ} \mathrm{C}$. The primary aim of this pilot study was to test the feasibility of the proposed protocol with the intention to design a main study. The primary questions were: (i) to what degree does body temperature increase or decrease with this protocol, (ii) whether epitympanic temperature is a suitable measure of core temperature using a recently developed, non-invasive device and (iii) if participants are able to tolerate the cold during inactive recovery. This pilot series included seven participants. After an acclimatization phase (15 minutes), participants exercised at $60 \%$ peak heart rate (20 minutes) followed by a seated, inactive recovery phase ( 15 minutes) in the cold. The mean ambient conditions were $-10.0 \pm 0.4^{\circ} \mathrm{C}$ and $66.1 \pm 8.6 \%$ relative humidity and no wind. The primary findings based on the feasibility criteria were that body temperature increased while exercising at an intensity of $60 \%$ HRpeak and decreased during inactive recovery by $-0.3 \pm 0.1^{\circ} \mathrm{C}$ (epitympanic temperature). Secondly, the agreement between epitympanic and esophageal temperature (mean difference $0.2^{\circ} \mathrm{C}, 95 \%$ confidence interval -0.5 to $0.0, p=0.095$ ) was better than in previous studies. Finally, all participants were able to tolerate the cold and complete the study despite thermal discomfort and shivering in the recovery phase. This protocol was successful in showing small changes in body temperature during exercise and recovery in the cold, though some modifications to the current protocol are recommended to elicit a larger effect size.

Keywords:

hypothermia - core body temperature - epitympanic temperature - cooling rate - cold exposure outdoor recreation

Citation:

Procter, E., Strapazzon, G., Gatterer, H., Wallner, B., Brugger, H. \& Burtscher, M. (2018): Monitoring body temperature during moderate intensity exercise and inactive recovery in the cold: a pilot study. Current Issues in Sport Science, 3:014. doi: 10.15203/CISS_2018.014 


\section{Introduction}

Exposure to cold ambient conditions poses a challenge for human thermoregulation. To maintain body temperature, heat production must be sufficient to offset heat loss to the environment.During exerciseorrecreation incoldenvironments, heat loss will depend on exercise intensity, insulation provided by clothing, ambient conditions and body composition (Noakes, 2000). Inability to maintain body temperature can result in accidental hypothermia, i.e. an involuntary drop in core body temperature $\left(T_{\text {core }}\right)$ below $35^{\circ} \mathrm{C}$. This is a potentially life-threatening condition with high morbidity and mortality (Brown, Brugger, Boyd, \& Paal, 2012; Haverkamp, Giesbrecht, \& Tan, 2018). The incidence of accidental hypothermia in outdoor recreationists is unknown but seems to be more common in outdoor activities performed at high altitude or in remote areas (Procter, Brugger, \& Burtscher, 2018).

The American College of Sports Medicine and National Athletic Trainers' Association have called for raised awareness on the prevention, recognition and management of hypothermia and other cold injuries in sport (Cappaert, Stone, Castellani, Krause, Smith, \& Stephens, 2008; Castellani et al., 2006). Any situation leading to decreased heat production (e.g. fatigue, inactivity, injury), increased heat loss (e.g. cold ambient conditions, insufficient insulation from clothing) or impaired thermoregulation (e.g. severe fatigue) could result in rapid cooling. Studies have shown that the combination of cold, wet and windy conditions in a fatigued state likely poses the greatest risk (Ainslie \& Reilly, 2003; Weller, Millard, Stroud, Greenhaff, \& Macdonald, 1997a; Young \& Castellani, 2001, 2007) and fatalities during outdoor sporting events have been reported ("Tote bei Zugspitz-Extremlauf," 2008).

Existing studies on thermoregulation in the cold focus primarily on alterations in the thermoregulatory response due to exertional fatigue after very long periods of exercise or simulated military training regimes, ranging from several hours (Ainslie, Campbell, Frayn, Humphreys, Maclaren, \& Reilly, 2002, 2003; Weller et al., 1997a, 1997b) to several days or weeks (Castellani et al., 2001, 2003). These conditions may not be reflective of general outdoor recreation, in which persons exercise for shorter periods and/or at lower intensity. It is unknown if heat loss in such cases could result in a decrease in $\mathrm{T}_{\text {core' }}$ and if so, the rate of cooling. However, $T_{\text {core }}$ refers to temperature measured invasively (e.g. pulmonary artery, distal third of the oesophagus) and obtaining a valid estimate of $\mathrm{T}_{\text {core }}$ in the field requires suitable devices (Strapazzon, Procter, Paal, \& Brugger, 2014). Due to a lack of such alternatives, practitioners must rely on devices that are not designed for use in prehospital conditions or reliable for measurement in hypothermic patients, such as infrared ear thermometry (Strapazzon et al., 2014). One of the few methods currently recommended for diagnosing the severity of hypothermia when invasive measures are not indicated or possible is thermistor-based epitympanic temperature $\left(T_{t y}\right)$, i.e. temperature measured with a thermistor probe deep in the ear canal (Brown et al., 2012; Brugger et al., 2013).
We present a series of pilot tests involving moderate intensity exercise and inactive recovery in the cold to monitor how body temperature changes under these conditions. The primary aim of this pilot study was to test the feasibility of the proposed protocol with the intention to design a main study. The primary questions were: (i) to what degree does body temperature increase or decrease with this protocol, (ii) whether $T_{\text {ty }}$ is a suitable measure of $T_{\text {core }}$ using a recently developed, noninvasive device and (iii) if participants are able to tolerate the cold during inactive recovery. Specific feasibility criteria were used to determine the success of this protocol.

\section{Methods}

\section{Participants}

Participants were recruited from the Department of Sport Science at the University of Innsbruck, Austria. The inclusion criteria were defined as persons between 18 and 50 years, male and female, capable of exercise according to the Physical Activity Readiness Questionnaire. Exclusion criteria included fever and chronic or acute diseases of the circulatory and/or respiratory system, airways, ears and nasopharynx. Written informed consent was obtained from all participants prior to participation in the study. The study was approved by the Institutional Review Board of the Department of Sport Science at the University of Innsbruck, Austria.

\section{Measures}

$\mathrm{T}_{\text {core }}$ was measured in the lower third of the esophagus using the insertion procedure described by Mekjavić \& Rempel (1990). $T_{t y}$ was measured in the external auditory meatus using a prototype of a thermistor probe developed by Cosinuss ${ }^{\oplus}$ (Munich, Germany; Figure 1). This device contains a thermistor sensor at the tip of the ear piece, which is placed in the ear canal close to but not touching the tympanic membrane. A second thermistor sensor is located in an external structure on the ear with the purpose to compare the temperature externally at the ear $\left(\mathrm{T}_{\text {aur }}\right)$ to that deeper in the ear canal. An ear cover was used to insulate the ear and the device (Figure 1). Temperature was recorded continuously by all devices.

Heart rate (HR) was measured continuously using a sport belt and watch (Polar ${ }^{\circledast} \mathrm{RS} 800 \mathrm{CX}$ ) and oxygen saturation using pulse oximetry on the finger (Nonin ${ }^{\oplus}$ Onyx Vantage 9590). Rating of perceived exertion was assessed using the 15-point Borg scale (Borg, 1982) and obtained at 2-minute intervals during the exercise phase. Thermal comfort was assessed using a 7-point scale (-3 cold, -2 cool, -1 slightly cool, 0 neutral, 1 slightly warm, 2 warm, 3 hot) and obtained at 2-minute intervals throughout the test. Shivering was based on visual observation by the tester or personal sensation by the participants. 


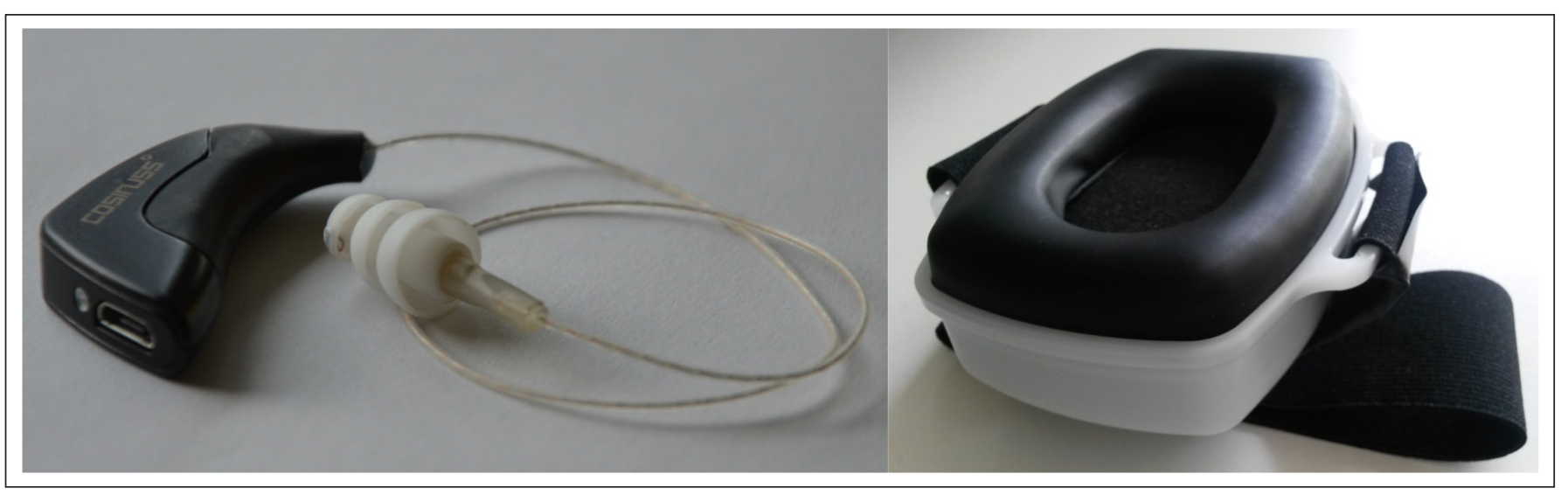

Figure 1: Prototype of a thermistor-based device for temperature measurement in the ear (left) and an ear cover to insulate the ear and device (right).

\section{Procedure}

Participants completed an incremental treadmill ergometer test to determine peak heart rate $\left(\mathrm{HR}_{\text {peak }}\right)$ using the following protocol from Burtscher, Förster, \& Burtscher (2008): (i) 2 min at $5 \mathrm{~km} / \mathrm{h}$ and $5 \%$ incline, (ii) $2 \mathrm{~min}$ at $5 \mathrm{~km} / \mathrm{h}$ and $10 \%$ incline, (iii) $1 \mathrm{~min}$ at $6 \mathrm{~km} / \mathrm{h}$ and $10 \%$ incline, (iv) every minute a $2 \%$ increase in inclination up to $20 \%$, and (v) every minute a $1 \mathrm{~km} / \mathrm{h}$ increase in speed until exhaustion. This test was done at least $72 \mathrm{~h}$ prior to further testing.

For the main tests, participants were asked to fast for at least six hours before testing. The oesophageal probe was inserted by a medical doctor before application of the epitympanic probe, ear cover and heart rate belt. The testing protocol had three phases. In the acclimatization phase, participants were seated and inactive for 15 minutes to allow for stabilization of temperature recordings. The exercise phase consisted of walking on a treadmill for 20 minutes at $60 \% \mathrm{HR}_{\text {peak }}$. To reach this intensity, an inclination of $10 \%$ and speed of $4.2 \mathrm{~km} / \mathrm{h}$ was set initially and adapted as necessary. In the recovery phase, participants were again seated and inactive for 15 minutes. Tests were done in a climate chamber with controlled temperature settings. The acclimatization phase was completed in a waiting room outside of the cold chamber to avoid pre-exercise cooling that can lead to a drop in $\mathrm{T}_{\text {core }}$ upon exercising, a so-called afterdrop (Giesbrecht \& Bristow, 1992, 1998; Grissom et al., 2010). To standardize the effect of thermal insulation of clothing on body temperature participants wore thermal clothing provided by the tester including a long-sleeved shirt and long underwear (estimated insulation value clo between 1.03 and 1.19) (ISO, 2005). They wore short socks and running shoes and did not wear gloves or a hat. The test was discontinued if $\mathrm{T}_{\text {core }}$ dropped below $35^{\circ} \mathrm{C}$ (to avoid any potential risk associated with lower $\mathrm{T}_{\text {core }}$ ) or if participants expressed discomfort severe enough to want to stop.

\section{Criteria to determine feasibility of this study}

The primary questions addressed in this pilot study were: (i) to what degree does body temperature increase or decrease with this protocol, (ii) whether $\mathrm{T}_{\text {ty }}$ is a suitable measure of $\mathrm{T}_{\text {core }}$ using a recently developed, non-invasive device and (iii) if participants are able to tolerate the cold during inactive recovery. The following criteria were used to determine the feasibility of this protocol based on these questions: (i) body temperature increased or remained constant during the exercise phase and decreased during the recovery phase in all participants, (ii) the mean difference between $\mathrm{T}_{\mathrm{ty}}$ and $\mathrm{T}_{\text {core }}$ during the exercise and recovery phases was $<1.3^{\circ} \mathrm{C}$ (Strapazzon et al., 2015) based on a Bland-Altmann plot and (iii) participants were able to tolerate the cold and complete the protocol.

\section{Sample size}

The sample size was determined using the results of a previous study of exercise at low intensity $\left(30 \% \mathrm{VO}_{2 \max }\right)$ in $0^{\circ} \mathrm{C}$ in which the mean change in body temperature was $-0.13 \pm 0.08^{\circ} \mathrm{C}$ in 15 minutes (Burtscher et al., 2012). The calculated sample size was six using an effect size of 1.6, alpha of 0.05 and power 0.8 . Seven participants were recruited.

\section{Statistical analysis}

Data were analysed using IBM SPSS Statistics 21. The Wilcoxon signed-rank test was used to compare different temperatures in the same person (e.g. $T_{\text {core }}$ vs. $T_{\text {ty }}$ ) or temperature at two time points. A Bland-Altmann plot and concordance correlation coefficient (CCC) were used to determine the agreement between $T_{\text {core }}$ and $T_{\text {ty }}$. Continuous measurements were analysed at 1-minute intervals. Results are shown as mean and standard deviation unless stated otherwise. The level of significance was defined as $\mathrm{p} \leq 0.05$. 


\section{Results}

Characteristics of the study participants are shown in Table 1. The following results refer to all participants $(n=7)$ unless stated otherwise. The mean age was $23.6 \pm 3.8$ years. The mean ambient conditions were $-10.0 \pm 0.4^{\circ} \mathrm{C}$ and $66.1 \pm 8.6 \%$ relative humidity and no wind. In the waiting room outside of the cold chamber the mean ambient temperature was $19.2 \pm 2.1^{\circ} \mathrm{C}$ and $53.5 \pm 10.1 \%$ relative humidity. The target intensity in the exercise phase of $60 \% \mathrm{HR}_{\text {peak }}$ was achieved (mean HR $59 \pm 2 \%$, $\mathrm{n}=7$ ). The oesophageal probe was displaced in participant 5 and 6 during transition to the treadmill for the exercise phase and $T_{\text {core }}$ could not be used in the analysis. The ear device stopped transmitting data in three cases (participants 3, 4 and 7) and had to be restarted manually, which resulted in 45 missing data points for $T_{\text {ty }}$ (12.6\% of all data points for $n=7$ ) and 75 data points for $T_{\text {aur }}^{\text {ty }}$ ( $21.0 \%$ of all data points for $\left.n=7\right)$. While restarting the device for participant 3 , the sensors were exposed to ambient air for four minutes and produced falsely low measurements for the remainder of the test; thus, $\mathrm{T}_{\text {ty }}$ and $\mathrm{T}_{\text {aur }}$ were not included for this participant in the analysis.

\section{Epitympanic temperature reflects core temperature in the cold}

The profiles of $\mathrm{T}_{\text {ty }}$ and $\mathrm{T}_{\text {core }}$ during cold exposure are shown in Figure 2. Mean $\mathrm{T}_{\text {ty }}$ was $35.7 \pm 0.6^{\circ} \mathrm{C}$ at the first measurement and increased to $36.9 \pm 0.3^{\circ} \mathrm{C}$ at the end of the acclimatization phase $(p=0.018, n=7)$. In the exercise phase, $T_{\text {ty }}$ did not increase until five minutes into the phase and increased on average by $0.2 \pm 0.4^{\circ} \mathrm{C}(p=0.279, n=6)$. Similarly, $T_{\text {ty }}$ did not decrease in the recovery phase until five minutes into the phase and decreased on average by $-0.3 \pm 0.1^{\circ} \mathrm{C}(\mathrm{p}=0.026, \mathrm{n}=6)$.

In comparison, $\mathrm{T}_{\text {core }}$ increased in the exercise phase by $0.4 \pm 0.3^{\circ} \mathrm{C}$ $(p<0.001, n=5)$ and decreased in the recovery phase by
$-0.2 \pm 0.2^{\circ} \mathrm{C}(\mathrm{p}<0.001, \mathrm{n}=5)$. A Bland-Altmann plot shows that mean $\mathrm{T}_{\text {ty }}$ was on average $0.2^{\circ} \mathrm{C}$ higher than mean $\mathrm{T}_{\text {core }}$ during the exercise and recovery phases $(95 \%$ confidence interval of the mean difference -0.5 to $0.0, p=0.095$; mean $\mathrm{T}_{\text {core }} 37.0 \pm 0.3^{\circ} \mathrm{C}$, mean $\mathrm{T}_{\text {ty }} 37.2 \pm 0.2 ; \mathrm{n}=4$; Figure 3 ); the correlation was weak (CCC $=0.26,95 \%$ confidence interval -0.28 to 0.68 ).

\section{Temperature external to the ear canal in the cold}

Cold exposure induced an immediate and significant decrease in $\mathrm{T}_{\text {aur }}$. The mean change in $\mathrm{T}_{\text {aur }}$ was $-1.7 \pm 0.8^{\circ} \mathrm{C}$ in the exercise phase and $-0.7 \pm 0.3^{\circ} \mathrm{C}$ in the recovery phase $(p=0.04$ between the two time points for both phases, $n=5$ ). On average $T_{\text {aur }}$ was $4.2 \pm 0.6^{\circ} \mathrm{C}$ lower than $T_{\text {ty }}$ in the exercise and recovery phases $(p=0.043, n=5)$.

\section{Thermal comfort and shivering in the cold}

Subjective ratings of thermal comfort varied widely between participants, though all participants reported decreasing thermal comfort with time. The median change during the exercise and recovery phase was -5 points (range -3 to -7 ) on the 7-point scale. In the exercise phase, participants rated thermal comfort between 0 and -3 (i.e. between neutral and cold) $62.8 \%$ of the time. In the recovery phase, participants rated thermal comfort between -2 and -3 (i.e. cool and cold) $71.4 \%$ of the time. Shivering was observed in the recovery phase in six participants at a mean $\mathrm{T}_{\text {core }}$ of $36.9 \pm 0.4^{\circ} \mathrm{C}$. The mean time to shivering once seated and inactive was $11 \pm 5 \mathrm{~min}$. One participant started shivering after four minutes and stopped shivering eight minutes later. The participant who showed no signs of shivering had the highest BMI.

Table 1: Characteristics of the study participants.

\begin{tabular}{|c|c|c|c|c|c|c|}
\hline Participant & Gender & Age (years) & Body mass (kg) & Height (cm) & BMI $\left(\mathrm{kg} / \mathrm{m}^{2}\right)$ & $\mathrm{HR}_{\text {peak }}(\mathrm{bpm})$ \\
\hline 1 & female & 22 & 55.8 & 170 & 19.3 & 200 \\
\hline 2 & male & 26 & 68.3 & 172 & 23.1 & 187 \\
\hline 3 & female & 20 & 66.8 & 171 & 22.8 & 194 \\
\hline 4 & female & 20 & 70.0 & 172 & 23.7 & 191 \\
\hline 5 & female & 21 & 69.3 & 168 & 24.6 & 195 \\
\hline 6 & male & 30 & 96.6 & 187 & 27.6 & 202 \\
\hline 7 & male & 26 & 75.2 & 173 & 25.1 & 190 \\
\hline
\end{tabular}




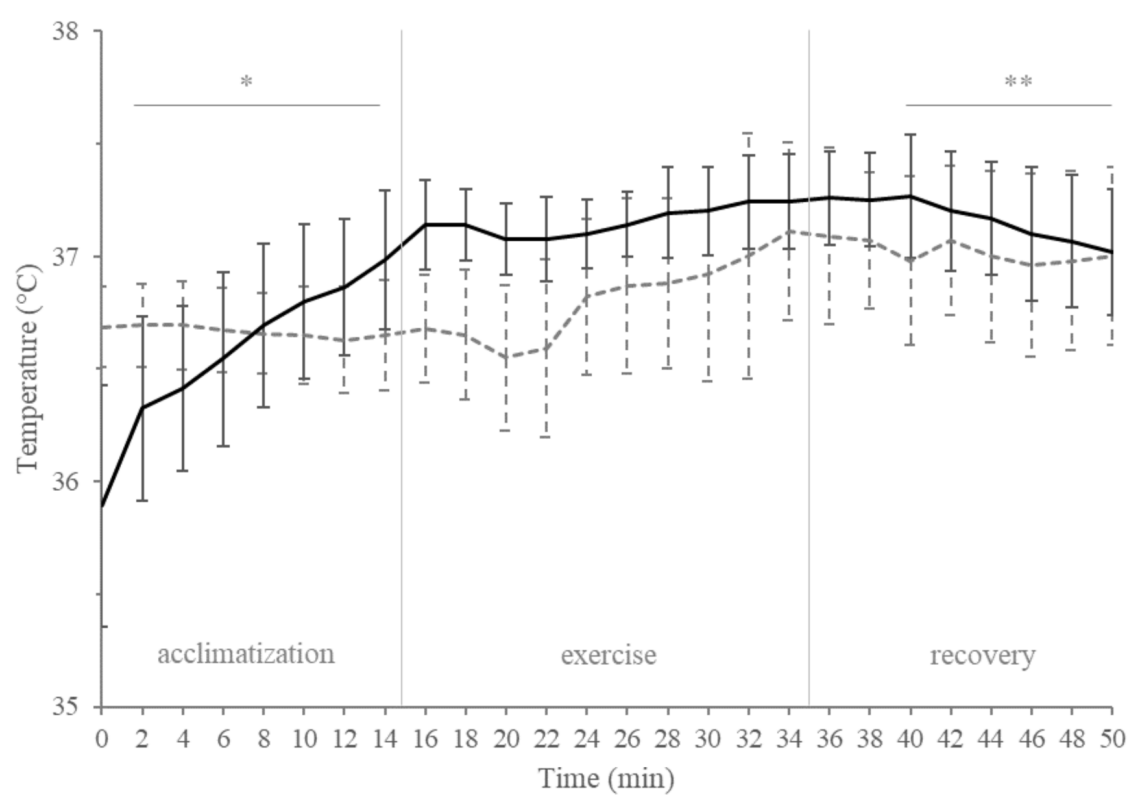

Error bars represent standard deviation.

* Epitympanic temperature between 0 and 14 minutes, $p=0.018$.

** Epitympanic temperature between 40 and 50 minutes, $p=0.026$.

Figure 2: Epitympanic temperature (solid line) and core body temperature (dashed line) during acclimatization, exercise and recovery in the cold.

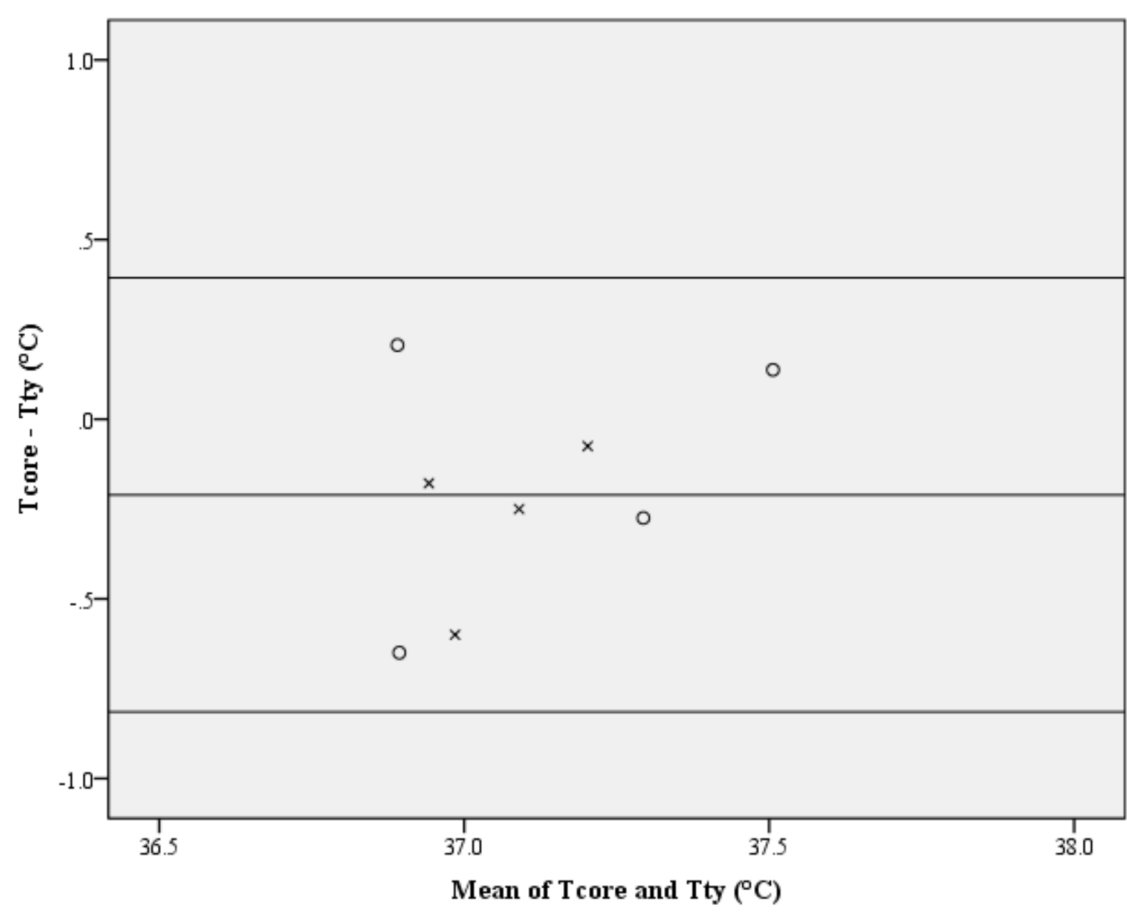

Figure 3: Bland-Altmann plot of mean core temperature $\left(T_{\text {core }}\right)$ and epitympanic temperature $\left(T_{\text {ty }}\right)$ in the cold during the exercise $(x)$ and recovery (o) phase $(n=4)$. The middle line indicates the mean of differences $\left(-0.2^{\circ} \mathrm{C}\right)$ and the upper and lower lines the limits of agreement (i.e., mean \pm 1.96 standard deviation, $0.4^{\circ} \mathrm{C}$ and $-0.8^{\circ} \mathrm{C}$ ). 


\section{Discussion}

This pilot study describes changes in body temperature during moderate intensity exercise and inactive recovery in cold ambient conditions $\left(-10^{\circ} \mathrm{C}\right)$. The primary findings based on the feasibility criteria were that body temperature increased while exercising at an intensity of $60 \% \mathrm{HR}_{\text {peak }}$ and decreased during inactive recovery. All participants remained normothermic $\left(T_{\text {core }}>35^{\circ} \mathrm{C}\right)$, even in the recovery phase. Secondly, the agreement between $T_{\text {ty }}$ and $T_{\text {core }}$ was better than in previous studies. Finally, all participants were able to tolerate the cold and complete the study despite thermal discomfort and shivering in the recovery phase. We conclude that this protocol can be used in a main study in future with some minor modifications. These findings are discussed below along with suggested modifications for a main study.

Previous studies on thermoregulation during cold exposure have shown that exercising at ca. 50-70\% maximum oxygen uptake $\left(\mathrm{VO}_{2 \max }\right)$ is sufficient to counteract heat loss and maintain body temperature in cold and windy conditions (Pugh, 1966; Weller et al., 1997a, 1997b; Burtscher et al., 2012). One study reported that during a $12-\mathrm{km}$, self-paced walk in the mountains (mean air temperature $6.4^{\circ} \mathrm{C}$, mean wind speed 2.8 $\mathrm{m} / \mathrm{s}$ ) participants reached this intensity only in the most difficult terrain, during which body temperature clearly increased (Ainslie et al., 2002). Over the course of the walk, the self-paced intensity varied between ca. $30 \%$ and $55 \% \mathrm{VO}_{2 \max }$. We found that 20 minutes of exercise at $60 \% \mathrm{HR}_{\text {peak }}$ in $-10.0 \pm 0.4^{\circ} \mathrm{C}(66.1 \pm 8.6 \%$ relative humidity and no wind) was associated with an increase in $T_{\text {core }}$. Thus, it seems that exercise at this intensity and under these conditions is associated with a positive heat balance in the absence of additional environmental stressors (wind, wet). In comparison, a previous study showed that introducing 10 $\mathrm{km} / \mathrm{h}$ wind during $0^{\circ} \mathrm{C}$ cold exposure at low intensity exercise $\left(30 \% \mathrm{VO}_{2 \max }\right)$ resulted in decreasing body temperature unless additional clothing was worn, including a cap, windbreaker jacket and trousers (Burtscher et al., 2012).

The decrease in body temperature in the recovery phase was less than expected under these conditions. This may be due to a combination of the following factors: adequate insulation from clothing, minimal exposure of skin to ambient air, lack of wind or precipitation, or shivering thermogenesis. Despite being normothermic, participants reported being cold and uncomfortable, which was supported by the presence of shivering in six of seven participants. It is challenging to compare the present findings with previous studies because of differences in environmental conditions and method of measuring body temperature. Ainslie et al. (2002) reported a drop in rectal temperature of ca. $1^{\circ} \mathrm{C}$ during a 30 -minute rest period on a 12-km self-paced hike, and three of twelve participants started shivering after 15 minutes. Other studies have reported decreasing body temperature at low intensity exercise $\left(30 \% \mathrm{VO}_{2 \max }\right)$ and ambient temperatures between $0^{\circ} \mathrm{C}$ and $5^{\circ} \mathrm{C}$ (Burtscher et al., 2012; Weller et al., 1997b, 1997a), though the absolute changes are not comparable because body temperature was reported as rectal or infrared-based ear temperature. The use of alternative temperatures without a valid measure of $T_{\text {core }}$ as a reference temperature is the main limitation of previous studies. The main strength of the current protocol is the use of $\mathrm{T}_{\text {core }}$. Future studies reporting alternative temperatures should also include a measure of Tcore.

Previous studies reporting thermistor-based $T_{\text {ty }}$ have shown that $T_{\text {ty }}$ reflects $T_{\text {core }}$ if the ear is insulated from cold ambient air (Strapazzon et al., 2015) and the ear canal is not cooled by water or snow (Skaiaa, Brattebø, Aßmus, \& Thomassen, 2015). Temperature should be measured as close to the tympanic membrane as possible because of the decreasing temperature gradient in the ear canal (Procter, Strapazzon, Rilk, Überbacher, \& Brugger, 2014). In a validation study of $\mathrm{T}_{\mathrm{ty}}$ the average difference between $\mathrm{T}_{\text {ty }}$ and $\mathrm{T}_{\text {core }}$ was $1.3^{\circ} \mathrm{C}$ during 10 minutes of cold exposure $\left(-18.7 \pm 1.0^{\circ} \mathrm{C}\right)$ without activity when the ear was insulated (Strapazzon et al., 2015). We found an average difference of $0.2^{\circ} \mathrm{C}$ between $T_{\text {ty }}$ and $T_{\text {core }}$ during the exercise and recovery phase. Apart from the difference in ambient temperature $\left(-18.7\right.$ vs $\left.-10.0^{\circ} \mathrm{C}\right)$, the better agreement may in part be explained by the positioning of the sensor, as this was a custom-made device designed for deeper insertion into the ear canal. Secondly, this device is the first to include a second sensor for $\mathrm{T}_{\text {aur }}$ and we found that the difference between $\mathrm{T}_{\text {ty }}$ and $\mathrm{T}_{\text {aur }}$ was more than $4^{\circ} \mathrm{C}$ despite that both sensors were insulated by the ear cover. This emphasizes the importance of correct positioning of the sensor to obtain accurate measurements. Additionally, it is known from previous studies that baseline readings take at least three minutes to stabilize (Skaiaa et al., 2015; Strapazzon et al., 2015), though our data show that this may be underestimated. The time to stabilization likely depends on the temperature of the ambient air, ear canal and sensor before insertion, and insulation of the head and ears. In one test, the ear cover was removed to restart the device and the external sensor was exposed to ambient air for four minutes. Within this time $\mathrm{T}_{\text {ty }}$ dropped by $1^{\circ} \mathrm{C}$ and $\mathrm{T}_{\text {aur }}$ by $9^{\circ} \mathrm{C}$ and values remained low after replacing the ear cover for over 20 minutes (these data were removed from the analysis).

In conclusion, this protocol was successful in showing small changes in body temperature during exercise and recovery in the cold, though some modifications to the current protocol are recommended to elicit a larger effect size. For example, a longer recovery phase or adding wind could result in more pronounced cooling and provide useful information on the duration until onset of rapid cooling. However, the thermal comfort of participants may limit how long this phase is tolerable. One limitation of these pilot tests was the small sample size and technical issues resulting in loss of data.

\section{Acknowledgements}

We thank the Department of Sport Science and all staff for assistance with the cold chamber and lending the technical clothing. 


\section{Funding}

This research was funded in part by a $\mathrm{PhD}$ research grant from the University of Innsbruck (Vice Rector for Research, 2015/3/ PSY/SPORT-22) and the Autonomous Province of Bozen/Bolzano (Abteilung Bildungsförderung, Protocol Nr. 404361).

\section{Competing Interests}

The authors have declared that no competing interests exist.

\section{Data Availability Statement}

All relevant data are within the paper.

\section{References}

Ainslie, P. N., Campbell, I. T., Frayn, K. N., Humphreys, S. M., Maclaren, D. P., \& Reilly, T. (2002). Physiological and metabolic responses to a hill walk. Journal of Applied Physiology, 92(1), 179-187. doi: 10.1152/jappl.2002.92.1.179

Ainslie, P. N., Campbell, I. T., Frayn, K. N., Humphreys, S. M., MacLaren, D. P. , \& Reilly, T. (2003). Physiological, metabolic, and performance implications of a prolonged hill walk: influence of energy intake. Journal of Applied Physiology, 94(3), 1075-1083. doi: 10.1152/japplphysiol.00683.2002

Ainslie, P. N., \& Reilly, T. (2003). Physiology of accidental hypothermia in the mountains: A forgotten story. British Journal of Sports Medicine, 37(6), 548-550. doi: 10.1136/ bjsm.37.6.548

Borg, G. A. V. (1982). Psychophysical bases of percieved exertion. Medecine and Science in Sports and Exercise, 14(5), 377-381. doi: 10.1249/00005768-198205000-00012

Brown, D. J. A., Brugger, H., Boyd, J., \& Paal, P. (2012). Accidental Hypothermia. N Engl J Med, 367(20), 1930-1938. doi: 10.1056/NEJMra1114208

Brugger, H., Durrer, B., Elsensohn, F., Paal, P., Strapazzon, G., Winterberger, E., ... Boyd, J. (2013). Resuscitation of avalanche victims: Evidence-based guidelines of the international commission for mountain emergency medicine (ICAR MEDCOM). Intended for physicians and other advanced life support personnel. Resuscitation, 84(5):539-546. doi: 10.1016/j.resuscitation.2012.10.020

Burtscher, M., Förster, H., \& Burtscher, J. (2008). Superior endurance performance in aging mountain runners. Gerontology, 54(5), 268-271. doi: 10.1159/000148649

Burtscher, M., Kofler, P., Gatterer, H., Faulhaber, M., Philippe, M., Fischer, K., ... Herten, A. (2012). Effects of lightweight outdoor clothing on the prevention of hypothermia during low-intensity exercise in the cold. Clinical Journal of Sport Medicine, 22(6), 505-507. : doi: 10.1097/ JSM.0b013e318257c9cc
Cappaert, T. A., Stone, J. A., Castellani, J. W., Krause, B. A., Smith, D., \& Stephens, B. A. (2008). National athletic trainers' association position statement: Environmental cold injuries. Journal of Athletic Training, 43(6):640-658. doi: 10.4085/1062-6050-43.6.640

Castellani, J. W., Stulz, D. A., Degroot, D. W., Blanchard, L. A., Cadarette, B. S., Nindl, B. C., \& Montain, S. J. (2003). Eightyfour hours of sustained operations alter thermoregulation during cold exposure. Medicine and Science in Sports and Exercise, 35(1), 175-181. doi: 10.1097/00005768-20030100000026

Castellani, J.W., Young, A. J., Degroot, D.W., Stulz, D. A., Cadarette, B. S., Rhind, S. G., ... Sawka, M. N. (2001). Thermoregulation during cold exposure after several days of exhaustive exercise. Journal of Applied Physiology (Bethesda, Md. : 1985), 90(3), 939-946.

Castellani, J., Young, A., Ducharme, M., Giesbrecht, G., Glickman, E., Sallis, R., \& Medicine, A. C. of S. (2006). American College of Sports Medicine position stand: prevention of cold injuries during exercise. Medicine and Science in Sports and Exercise, 38(11), 2012-2029. doi: 10.1249/01. mss.0000241641.75101.64

Giesbrecht, G. G., \& Bristow, G. K. (1992). A second postcooling afterdrop: more evidence for a convective mechanism. Journal of Applied Physiology (Bethesda, Md.: 1985), 73(4), 1253-1258. doi: 10.1152/jappl.1992.73.4.1253

Giesbrecht, G. G., \& Bristow, G. K. (1998). The convective afterdrop component during hypothermic exercise decreases with delayed exercise onset. Aviation Space and Environmental Medicine, 69(1), 17-22.

Grissom, C. K., Harmston, C. H., McAlpine, J. C., Radwin, M. I., Ellington, B.,Hirshberg, E. L., \&Crouch, A. (2010).Spontaneous endogenous core temperature rewarming after cooling due to snow burial. Wilderness and Environmental Medicine, 21(3), 229-235. doi: 10.1016/j.wem.2010.06.007

Haverkamp, F. J. C., Giesbrecht, G. G., \& Tan, E. C. T. H. (2018). The prehospital management of hypothermia - An upto-date overview. Injury, 49(2):149-164. doi: 10.1016/j. injury.2017.11.001

ISO. (2005). Ergonomics of the thermal environment: Estimation of the thermal insulation and evaporative resistance of a clothing ensemble. Geneva: International Organization for Standardization.

Mekjavić, I. B., \& Rempel, M. E. (1990). Determination of esophageal probe insertion length based on standing and sitting height. Journal of Applied Physiology (Bethesda, Md. : 1985), 69(5), 376-379. doi: 10.1152/jappl.1990.69.1.376

Noakes, T. D. (2000). Exercise and the cold. Ergonomics, 43(10), 1461-1479. doi: 10.1080/001401300750003907

Procter, E., Brugger, H., \& Burtscher, M. (2018). Accidental hypothermia in recreational activities in the mountains: A narrative review. Scandinavian Journal of Medicine and Science in Sports, (Sept 11), [Epub ahead of print]. doi: $10.1111 /$ sms. 13294 
Procter, E., Strapazzon, G., Rilk, C., Überbacher, N., \& Brugger, H. (2014). Temperature gradient in the inner ear canal and implications for epitympanic temperature measurement. High Altitude Medicine \& Biology, 15(2), A281.

Pugh, L. (1966). Accidental Hypothermia in Walkers, Climbers, and Campers: Report to the Medical Commission on Accident Prevention. British Medical Journal, 1(5480), 123129. doi: $10.1136 /$ bmj. 1.5480 .123

Skaiaa, S. C., Brattebø, G., Aßmus, J., \& Thomassen, Ø. (2015). The impact of environmental factors in pre-hospital thermistorbased tympanic temperature measurement: A pilot field study. Scandinavian Journal of Trauma, Resuscitation and Emergency Medicine, 23, 72. doi: 10.1186/s13049-015-0148-5

Strapazzon, G., Procter, E., Paal, P., \& Brugger, H. (2014). Prehospital core temperature measurement in accidental and therapeutic hypothermia. High Altitude Medicine \& Biology, 15(2), 104-111. doi: 10.1089/ham.2014.1008

Strapazzon, G., Procter, E., Putzer, G., Avancini, G., Dal Cappello, T., Überbacher, N., ... Brugger, H. (2015). Influence of low ambient temperature on epitympanic temperature measurement: A prospective randomized clinical study. Scandinavian Journal of Trauma, Resuscitation and Emergency Medicine, 23, 90. doi: 10.1186/s13049-015-0172-5

Tote bei Zugspitz-Extremlauf. (2008). Retrieved April 30, 2018, from http://www.spiegel.de/panorama/tote-bei-zugspitzextremlauf-sie-haben-sie-in-ihr-unglueck-rennenlassen-a-565745.html

Weller, A. S., Millard, C. E., Stroud, M. A., Greenhaff, P. L., \& Macdonald, I. A. (1997a). Physiological responses to a cold, wet, and windy environment during prolonged intermittent walking. The American Journal of Physiology, 272, R2025R2033.

Weller, A. S., Millard, C. E., Stroud, M. A., Greenhaff, P. L., \& Macdonald, I. A. (1997b). Physiological responses to cold stress during prolonged intermittent low- and highintensity walking. The American Journal of Physiology, 272(6 Pt 2), R2025-R2033.

Young, A. J., \& Castellani, J. W. (2001). Exertion-induced fatigue and thermoregulation in the cold. Comparative Biochemistry and Physiology - A Molecular and Integrative Physiology, 128(4):769-776. doi: 10.1016/S1095-6433(01)00282-3

Young, A. J., \& Castellani, J. W. (2007). Exertional fatigue and cold exposure: mechanisms of hiker's hypothermia. Applied Physiology, Nutrition, and Metabolism, 32(4), 793-798. doi: 10.1139/H07-041 